1,200,000 acres of land, now dry and barren, thus providing farm land for some 75,000 people. The irrigated area, it is expected, will ultimately be the home of more than a million.

\section{Tuberculosis in the Navy}

Ar a meeting of the Section of Epidemiology and State Medicine of the Royal Society of Medicine on March 28, Surgeon-Rear-Admiral S. F. Dudley and Surgeon-Commander W. G. C. FitzPatrick read a paper on epidemiology in the Royal Navy, especially as regards the use of miniature radiography. They stated that tuberculosis is an occasional disease of sailors. Although its ravages were much greater in the last century, there has been no decline in its prevalence in the present century, in spite of energetic measures to prevent it. This is due to the unpreventable degree of overcrowding which must exist in warships and the presence of numerous unsuspected cases of open pulmonary tuberculosis. Measures designed to weed out these sources of infection have hitherto failed; little effect on total incidence can be expected from the $\mathrm{X}$-ray examination of recruits or limited numbers of contacts. Periodic X-ray examination of the total force by the usual technique is considered impracticable, therefore the more rapid and economic technique of mass miniature radiography has been instituted. Some preliminary results on the first twenty thousand examinations were given and the organization of the first Naval Miniature Radiographic Department was described.

\section{Jewish Population of Palestine}

The Statistics Department of the Jewish Agency Executive records that the Jewish population of Palestine has increased by immigration and natural increase from 174,606 in November 1931, according to the official census of that time, to 488,600 in September 1940. This estimate is 30,000 higher than that of the Government, which puts the Jewish population at 456,743 in June 1940 . The Jews now represent 31.2 per cent of the settled population of Palestine. In 1931 the percentage was $16^{\circ} 9$, and in 1922 , when 83,790 Jews were enumerated after the British occupation, it was $11 \cdot 1$.

\section{Health of Iceland}

According to the latest annual report of $\mathrm{Dr}$. Vilmundur Jonsson, director of public health, health conditions in Iceland are generally satisfactory. The death-rate is 10.2 per 1,000 , and the infantile mortality-rate of 29 per 1,000 is remarkably low; deficiency diseases are infrequent, rheumatic fever and diabetes are rare, and diphtheria, which was once very fatal among children, is now kept in check by immunization. On the other hand, there is a relatively high rate for tuberculosis, and pneumonia is an important cause of death.

\section{Steel Armouring of Cables}

Mr. R. W. L. PhILLIPs, borough electrical engineer of Bedford, has an article in the Electrical Review of
January 10 on the present prohibition of steel armouring on electric cables. In the early days of electricity supply, the practice of laying cables direct in the ground without conduits or some similar protection was looked upon by many as being risky, principally because in many soils the lead sheathing would be liable to attack by corrosive salts. As a matter of fact, this did occur until a suitable compound was found for impregnating the protective jute covering. Armouring was added as a safeguard against mechanical damage. The usual method that is adopted to protect a cable that is to be laid direct in the ground, is to 'serve' the lead sheathing with a layer of jute before laying on the armouring, and a further layer of impregnated jute to protect the armouring from the corrosive action of the soil. The first layer acts as a bed for the armouring, thus preventing it damaging the lead; but, in Mr. Phillips's opinion, the success of direct-laid underground cable is due not so much to the armouring as to the double layer of impregnated jute so made necessary.

It remains to be considered whether the armouring of the cable, as normally provided, is a sufficient mechanical protection to justify its expense and the use of so much steel which is urgently required for other purposes at the present time. Mr. Phillips's experience in Bedford is helpful here. In this borough some 230 miles of medium voltage cable, 80 miles of cable up to 3,000 volts and about 45 miles of higher voltage cables, all without armouring, were laid in the ground. In the manufacture of unarmoured cables for direct laying, it is in some cases the practice to provide the cable with two layers of impregnated paper directly over the lead, as a protection against chemical action. This is followed by a final covering of two layers of doubly impregnated jute. If it could be done without unduly putting up the cost of manufacture, a better method would be to 'braid' the final jute covering under a stream of compound when manufacturing the cable. There are two incidental advantages in the use of an unarmoured cable. It weighs less, which affects both transport and handling; it is easier to joint (this is especially useful when making service connexions to lowvoltage distributors). Mr. Phillips quotes data in connexion with an extensive and intensive electrification of a rural area of about 200 square miles. In the majority of the villages in this area it actually cost less to lay unarmoured low-voltage distributors than to provide the same service by means of overhead wires. Some of the cables in the Bedford area have been in the ground many years and no troublo attributable to the absence of armouring has been experienced.

\section{Mummification in America}

Dr. Aleš HrduIČKa, of the Smithsonian Institution, Washington, prefaces extracts from his diaries of 1936-38, when he was exploring for mummies on the Aleutian Islands, now appearing in the Scientific Monthly (January 1941), with some general considerations on the practice of mummification. As is 